\title{
Una Historia De Vampiros Y Su Transformación De Ser Solo Monstruos a Figuras Monstruosas, Trágicas Y Románticas
}

\author{
Michael Cartmill, $\mathrm{PhD}^{1}$ a, Mary McFadden ${ }^{2}$ b \\ ${ }^{1}$ Translator, Dixie State University, ${ }^{2}$ Author, Dixie State University \\ Keywords: vampiros, Carl Jung, folclore, ficción literaria \\ https://doi.org/10.36898/001c.28022
}

Curiosity: Interdisciplinary Journal of Research and Innovation

\begin{abstract}
A lo largo de la historia de relatos sobre vampiros-del folclore a la ficción literaria-la descripción de estas criaturas inhumanas se ha metamorfoseado del mito de Carl Jung, nacido del arquetipo de la Sombra, en tres arquetipos vampíricos distintos, ninguno de los cuales ha dejado atrás sus orígenes míticos por completo. Estos arquetipos se presentan como el vampiro monstruo, el vampiro trágico y el vampiro romántico. Al examinar la etimología de la palabra vampiro, el folclore vampírico antiguo, la literatura vampírica temprana hasta la moderna y el cine vampírico temprano hasta el contemporáneo, este trabajo mostrará que el vampiro ya no está relegado al papel de antagonista contra el protagonista de la historia. El vampiro podría ser el antihéroe trágico o el protagonista de un relato. Mucho folclore temprano sobre los vampiros se representa por medio de relatos que los seres humanos contaban para explicar la maldad y la mala suerte que sufría su familia. Sin embargo, cuando el vampiro entró en la ficción literaria temprana, los autores empezaron a ejercer su poder de manipular la narrativa vampírica, creando nuevas construcciones vampíricas. Este cambio en las caracterizaciones de vampiros es un comentario alegórico sobre la lucha del hombre para superar su naturaleza pecaminosa al buscar la salvación por medio de la redención.
\end{abstract}

Mientras algunos investigadores notan la existencia de un arquetipo vampírico, Carl Jung, fundador de la psicología analítica, creyó que los monstruos, tal como el vampiro, no eran arquetipos en sí, sino mitos, nacidos de arquetipos. Mientras las creencias de Carl Jung clasificarían a un vampiro como un mito, yo pienso mostrar que desde relatos tempranos hasta modernos de vampiros muestran un cambio paulatino del mito del monstruo a tres representaciones o arquetipos de vampiros separados. Una representación de vampiros que permanece es la criatura aterradora originaria, tal como está caracterizado por el arquetipo de la Sombra de Carl Jung; otra representación es el héroe byroniano trágico y torturado-o antihéroe; y la última progresa por las primeras dos etapas hasta las figuras literarias de fantasía modernas, seductoras, a menudo romantizadas: el vampiro heroico. Yo pienso mostrar que estas tres representaciones distintas, aunque sin dejar atrás por completo sus orígenes míticos, han llegado a ser sus propios arquetipos, y el desarrollo de estos arquetipos refleja el camino del ser humano para encontrar la redención de su propia naturaleza pecaminosa, o deseos oscuros, sean basados en creencias judeocristianas, otras creencias religiosas, o en un sistema de creencias secular moralista.

\footnotetext{
a Michael Cartmill is a Director of Global Education and a Professor of Spanish at Dixie State University.

b Mary McFadden is an Instructor of English at Dixie State University.
} 
Carl Jung cree que hay cuatro arquetipos principales: el Yo, la Persona, la Sombra y el Ánima/Ánimus. Estos arquetipos son imágenes primordiales-restos arcaicos impresos en la subconsciencia, la parte de la mente donde el procesamiento automático ocurre. Estas imágenes primordiales son legados de nuestros antepasados. Jung declara:

El término "arquetipo" a menudo se malinterpreta con el significado de una cierta imagen o motivo mitológico definido. Pero esto no sería más que una representación consciente... El arquetipo es, al contrario, una tendencia heredada de la mente humana para formar representaciones de motivos mitológicos-representaciones que varían grandemente sin perder su patrón básico. (Jung, 1968, p. 120)

Jung afirma que cada personalidad tiene su lado oscuro que es la puerta a la subconsciencia y a los sueños. Por medio de esta puerta, la figura de la Sombra arquetípica entra en nuestros sueños. Los mitos no son arquetipos en sí. Son creados por arquetipos. El arquetipo de la Sombra es la parte escondida de la psiquis humana-la parte que nos da miedo por su oscuridad. Este miedo causa que nuestra mente construya mitos para representar esta parte escondida de nuestra psique (Jung, 1968, p. 38). Siguiendo la lógica de Jung, un vampiro no puede ser un arquetipo en sí; más bien es un mito nacido del arquetipo de la Sombra.

Entonces, ¿qué hace que el vampiro, o cualquier otra criatura del mito, sea la personificación del arquetipo de la Sombra de Carl Jung? Cuentos de criaturas malas abundan en la época antes del cristianismo. Son la representación del lado más oscuro del ser humano temprano, las imágenes que Jung afirma se legan a los descendientes por medio de su ADN, tal como en Lamentaciones 5:7 en la Santa Biblia, el hijo sufre las iniquidades de su padre (English Standard Version Bible, 2001, Lamentations 5:7). Estas iniquidades son nuestro pecado, y el arquetipo de la Sombra de Jung bien puede ser en sí una representación de este pecado y el mito del vampiro su manifestación.

En su libro El poder del mito, un manuscrito de una conversación entre Joseph Campbell, mejor conocido por su teoría de la jornada del héroe arquetípico, y el periodista Bill Moyers, Campbell afirma:

Estos pedazos de información de los tiempos antiguos, que tienen que ver con los temas que han mantenido la vida humana, creado civilizaciones e informado religiones a lo largo de milenios, se tratan de problemas profundos interiores, misterios interiores, umbrales interiores de paso, y si no se sabe lo que son las señales de guía en el camino, uno tendrá que solucionarlo uno mismo. (Campbell \& Moyers, 1998, p. 4)

Al respecto, Moyers interpreta que el significado de Campbell ser, "[N]osotros contamos historias para intentar aceptar el mundo, para harmonizar nuestras vidas con la realidad" (Campbell \& Moyers, 1998, p. 
4). Es la naturaleza humana preguntar, “¿Por qué está pasando esto?” En ese deseo de reconciliar la disonancia cognitiva que se siente cuando no podemos unir lo que vemos con lo que entendemos, nuestra mente busca una nueva comprensión por medio de la creación de mitos.

\section{Folclore vampírico temprano}

Muchos países y culturas tienen alguna forma de folclore vampírico en su historia. Estos relatos, tal como Campbell y Moyers sugieren, tienen orígenes en el miedo de los que simplemente intentan sacar en limpio el mundo a su alrededor. He aquí unos cuantos ejemplos.

\section{Ábhartach (celta)}

Ábhartach, un cacique cruel, enano celoso y hechicero, del pueblo irlandés Slaghtaverty en Londonberry, reinó durante los siglos V y VI. Algunas historias dicen que cayó hasta su muerte cuando escaló el alféizar afuera de la ventana de la habitación de su esposa para espiarla engañándolo. Otras versiones de su relato dicen que un cacique vecino lo mató. Ábhartach se enterró en una posición vertical, en vez de la posición prona típica, tal como muchos gobernantes de esa época. Al día siguiente, el hechicero volvió de la tumba y exigió que sus súbditos cortaran las venas de sus muñecas y llenaran un cuenco con su sangre para que la consumiera. La sangre fue necesaria para sostenerle su vida. Ábhartach, una vez más, fue asesinado por otro cacique o por un asesino y enterrado verticalmente. Él volvió de entre los muertos, una vez más, la siguiente noche, para continuar su reinado del terror. El cacique o asesino mató a Ábhartach por última vez. Esta vez, siguiendo la sugerencia de un druida, lo enterraron de cabeza, atrapándolo en su tumba (Bane, 2020, p. 13; Gallagher, 2017 , p. 26). Tal como es el caso con la mayoría de las historias de vampiros modernos, Ábhartach empezó como humano, vuelve de entre los muertos y bebe sangre.

\section{Vetal (indio)}

Una historia del siglo XI en sánscrito, Baital Pachisi, o Vetala Panchevimshati, traducida por sir Richard Francis Burton a mediados del siglo XIX y renombrado Vikram y el vampiro, es un relato de un vetal y un rey llamado Vikram. El vetal es un espíritu maligno que puede ocupar los cadáveres, es mitad hombre mitad murciélago con una cola corta achaparrada. Bebe sangre humana y devora sacrificios de carne humana. Su semblante espantoso causa que los que lo observan se vuelvan débiles y se desmayen de temor. Al descansar los vetales pasan su tiempo colgados de árboles cerca de los cementerios (Bane, 2020, p. 28-29). La afición de esta criatura antigua por colgarse de los árboles y su forma parcial de murciélago probablemente fueron la inspiración de los vampiros literarios con la habilidad de convertirse en murciélagos. 


\section{Berwick (inglés/escocés)}

En el área más septentrional de Inglaterra, que colinda con el río Tweed, hay una aldea nombrada Berwick, o Berwick-Upon-Tweed. Aunque el pueblo estaba situado en Inglaterra, se incorporó bajo el reino escocés durante el siglo XII. En 1196, había un comerciante próspero pero inescrupuloso que murió de la peste negra. Después de su entierro, relatos escritos dicen que vagaba por las calles por la noche, propagando la enfermedad al deambular y anunciaba que no habría paz para los aldeanos a menos que prendieran fuego a su cadáver y este se quemara hasta ser ceniza. El vampiro de Berwick solo dejó su tumba por la noche y volvió a ella cada día antes del amanecer. Cuando los aldeanos por fin exhumaron su cadáver y lo quemaron, aproximadamente la mitad de los aldeanos habían perecido a causa de la peste negra (Bane, 2020, p. 33; Summers, 1996, p. 82-83). El vampiro de Berwick es un ejemplo temprano de los muertos vivientes resucitándose de la tumba solo por la noche para aterrorizar a los vivientes, de manera muy similar a muchos vampiros de la ficción literaria.

\section{Upiro (eslavo)}

El upiro es un vampiro antiguo eslavo que se creía fue creado de una de dos formas posibles. Cuando un hereje, alguien cuyas creencias quedan fuera del dogma de una religión, muere, esa persona podría llegar a ser un upiro. Alternativamente, el engendro de una bruja y un hombre lobo nacería un upiro. Los métodos para matar uno de ellos se asemejan notablemente a las prácticas para acabar con muchos vampiros encontrados en la literatura moderna. La tumba de un upiro tiene que ser empapada en agua bendita y hay que clavar una estaca por su pecho. El upiro también podría expirar por decapitación o incineración (Bane, 2020, p. 137-138; Melton, 1994, p. 525).

\section{Brucolaco (griego)}

Los cuentos griegos del brucolaco varían a lo largo de su historia temprana. Inicialmente, eran más espíritu en su naturaleza que seres físicos propiamente dichos, eventualmente transformándose en las representaciones tradicionales de los muertos vivientes. Se pensaba que los brucolacos resucitaban de las tumbas para buscar miembros de la familia, atacándolos y chupando su sangre. Quemar un brucolaco era la única manera infalible de destruirlo (Bane, 2020, p. 149-150).

\section{El punto clave}

El punto clave de estos cuentos tempranos de criaturas vampíricas es que sin importar como se llamen, ellas todavía no se han transferido de la subconsciencia humana a la mente consciente-del reino del mito al arquetipo. Son representativos del mito del monstruo de Jung, y tal como afirma Campbell, nacidos para explicar lo inexplicable.

Al mirar los mitos de vampiros del folclore temprano, la pregunta surge: ¿Qué propósito sirvió la creación del mito del vampiro? Campbell dice, "Cuando el relato está en la mente, entonces uno ve su relevancia con algo que pasa en su propia vida. Le da perspectiva de lo que le pasa” (Campbell \& Moyers, 1998, p. 4). Muchos relatos de folclore comienzan con la muerte 
y el deseo del ser humano de explicar lo que no se explicaba por la falta de comprensión científica. Supongamos que una plaga u otro virus aniquilara una familia entera o la mayoría de una aldea, con el conocimiento de ciencia limitado y la ira de Dios que previamente había tomado la forma de plagas. En ese caso, los seres humanos podrían considerarlo la ira de Dios azotándolos, que han hecho algo para merecer su disgusto, y ellos tal vez podrían asumir que su lugar en el cielo está en peligro. En el libro de Jung El yo no descubierto, él declara,

Sería un pensamiento insoportable que tuviéramos que tomar la responsabilidad personal por tanta culpabilidad. Por lo tanto, preferimos confinar el mal a criminales individuales... mientras nos lavamos las manos en la inocencia... el mal, tal como muestra la experiencia, yace en el hombre-a menos que, según el punto de vista cristiano, uno esté dispuesto a postular un principio metafísico del mal. La gran ventaja de este punto de vista es que exonera a la consciencia humana de una responsabilidad demasiado pesada y se la endiña al diablo, con la apreciación psicológica correcta del hecho de que el hombre sea mucho más la víctima de su constitución psíquica que su inventor. (Jung, 2006, p. 96-97)

En otras palabras, si los seres humanos crean un monstruo-un mito-el cual es el perpetrador de su mala suerte, ya no son responsables. Este monstruo hace los mandatos malignos de su amo, presuntamente Satanás mismo. Entonces no son los humanos los que pierden el favor de Dios. De hecho, al intentar destruir activamente al monstruo (p. ej. por medio de decapitarlo, clavarlo, quemarlo, etc.), ellos hacen la voluntad de Dios y posiblemente ganan su favor.

\section{De mito a arquetipo}

Entonces ¿cómo cambió el vampiro del reino del mito al arquetipo? La definición de la palabra arquetipo del Diccionario inglés de Oxford, derivada de algunos de los usos más tempranos conocidos de la palabra, "El patrón o modelo original del cual se hacen copias; un prototipo" ("Archetype, n.," 2020), muestra que ejemplos de vampiros del folclore y la ficción literaria tempranos pueden dar a luz a lo que los lectores modernos considerarían un arquetipo de vampiro, un patrón o modelo original. Esto ocurre al trasladar el vampiro de la inconsciencia a la mente consciente.

$\mathrm{Si}$ los humanos primitivos crean un mito de monstruo-vampiro, del arquetipo de la Sombra, para comprender lo que no pueden explicar, entonces ¿qué pasa a este mito cuando el intelecto humano evoluciona? Jung declara, "El arquetipo esencialmente es un contenido inconsciente que se altera al llegar a ser consciente y al ser percibido, y toma su matiz de la consciencia individual en la cual aparece por casualidad" (Jung, 1968, p. 20). Mientras el mito del vampiro empezó como una representación inconsciente del arquetipo de la Sombra, los numerosos relatos en el folclore literario junto con la ficción 
literaria han trasladado al vampiro de nuestra subconsciencia a nuestra consciencia, formando un patrón o modelo que forma la base de tres arquetipos básicos de vampiros-el vampiro monstruo, el vampiro trágico y el vampiro romántico/héroe.

Aunque hay muchos ejemplos de estos arquetipos entre los vampiros literarios y cinemáticos, para este trabajo, voy a dar unos ejemplos de cada uno, pero me enfocaré por la mayor parte en uno de cada arquetipo.

\section{Definir el vampiro}

Para comprender el cambio de paradigma de las representaciones de vampiros, primero es necesario comprender qué califica como un vampiro. Los orígenes de la palabra "vampiro" difieren de los orígenes de la sabiduría tradicional. Los orígenes de la palabra son debatibles, e historias del vampirismo preceden la palabra misma. En su artículo "La historia de la palabra 'vampiro," Katharina M. Wilson afirma que hay cuatro teorías populares en cuanto al origen de la palabra; sin embargo, ella sugiere que las raíces más ampliamente aceptadas con las eslavas (Wilson, 1985, p. 577).

La primera de estas cuatro teorías viene del lingüista austriaco de los finales del siglo XIX, Franz Miklosich. En su libro Etymologisches Wörterbuch der Slavischen Sprachen, Miklosich sugiere que, "La palabra 'vampiro' y sus sinónimos eslavos 'upior,' 'uper' y 'upyr' son todos derivados del 'uber' turco-bruja” (Wilson, 1985, p. 577).

La segunda teoría favorece la idea que una fuente potencial de la palabra "vampiro" es de la palabra raíz "pi" o " $\pi i \nu \omega$, , del verbo griego de beber, combinada con el prefijo "va” o "av." En su libro El vampiro en la tradición y la leyenda Montague Summers sugiere que mientras esto es una fuente posible de la palabra, es una fuente improbable y que la superstición griega del brucolaco está cargada del origen eslavo (Summers, 1929, p. 18). Dependiendo de la fuente, algunos creen que el mito eslavo del brucolaco tiene orígenes griegos, mientras otros insisten que el brucolaco griego tiene orígenes eslavos.

La tercera creencia es que el origen de la palabra es la palabra húngara "vampir." Esta es una teoría popular entre los ingleses y los estadounidenses; sin embargo, no es probable dado que el primer uso de la palabra húngara sucede después del uso del término en muchos idiomas occidentales (Wilson, 1985, p. 578).

La fuente más universalmente aceptada es de origen eslavo. Los bien conocidos hermanos Grimm están entre los que favorecen esta teoría (Wilson, 1985, p. 577). Aunque la mayoría de los investigadores concuerdan que la palabra vampiro es de origen eslavo, según Brian Cooper, en su artículo "La palabra vampiro: su forma y origen eslavos," el deletreo de las varias formas de vampiro que comienzan con "vam" vino de los eslavos adueñándose de la palabra adulterada de los mismos griegos (Cooper, 2005, p. 262).

El Diccionario inglés de Oxford tiene el uso más temprano de la palabra vampiro del texto de 1741 de Charles Forman, llamado Algunas preguntas y observaciones sobre la revolución en 1688. Su entrada sobre los vampiros 
también incluyó la impresión de "Los viajes de tres caballeros ingleses" en The Harleian Miscellany ("Vampire, n.," 2020). Aunque este relato fue publicado en 1745, cuenta los viajes de tres caballeros ingleses en 1734. De este texto:

Los vampiros, los cuales salen de las tumbas por la noche, llegan deprisa a las personas durmiendo en sus camas, chupan toda su sangre y las destruyen... Los que son destruidos por ellos, después de su muerte, llegan a ser vampiros; así que, para prevenir así la propagación del mal, se encuentra necesario clavar una estaca por el cadáver, del cual, en esta ocasión, la sangre fluye como si la persona estuviera viva. (Johnson \& Oldys, 1745, p. 358)

Mientras el Diccionario inglés de Oxford da la fecha de 1741 como el primer uso de la palabra vampiro, tal como su nombre sugiere, este es el primer uso de la palabra en inglés, lo cual hace completamente posible que uno de los cuatro posibles orígenes que Wilson nota sea el origen real de la palabra.

Lo que es importante destacar es que cualquier origen de la palabra "vampiro" que se cree entre los varios lingüistas, ninguno de los orígenes, tal como se relacionan con los vampiros, precede los finales del siglo XVIII. Sin embargo, relatos de conocimiento tradicional de vampiros, historias de los con rasgos de vampiros sí lo preceden. Por esta razón, la evolución del vampiro, tal como se trata en este trabajo, se refiere no solo a la criatura que así se nombra sino también la criatura que se representa.

La caracterización de un vampiro es subjetiva y de ninguna forma homogénea. Si uno basara su comprensión de un vampiro en la literatura del silgo XIX (p. ej. Drácula) y cierta cultura pop actual (p. ej. Vampiros de John Carpenter), se podría considerar a un vampiro como una criatura de muerto viviente sin alma que no pueda ver su propio reflejo, que tenga dos colmillos largos superiormente en su boca, los cuales usa para perforar las arterias de sus víctimas, y que pueda hipnotizar a su presa humana. Sus debilidades son el ajo, los rayos del sol, ser estacado, ser decapitado, el fuego y el agua bendita. Sin embargo, un vistazo al folclore antiguo vampírico abarca una definición más amplia de un vampiro. Las plagas que dejan ampollas; la rabia que causa echar espuma por la boca; los pacientes en estado de coma considerados muertos pero que se despiertan; y posiblemente los que sufren de porfiria, lo cual causa la erupción y ampollas en la piel por los rayos del sol, todos los cuales se consideraban evidencia de alguna forma de posesión demoniaca o vampírica. Esta evidencia provocó a los aldeanos asustados a desenterrar los fallecidos, estacarlos y decapitarlos-añadiendo más credibilidad a las historias de vampirismo. Algunos de estos relatos tempranos incluyeron cadáveres exhumados con uñas y cabello que continuaron creciendo y lo que parecía ser nueva piel saludable, y algunas historias mencionan la evidencia de una mortaja devorada en el ataúd del percibido vampiro. Si varios miembros de la familia morían en un corto tiempo, los habitantes creían que el primero que había fallecido se había despertado de entre los muertos como vampiro y maldijo a los otros miembros de la familia. Esto causó a mucha gente creer que las 
víctimas de la peste negra eran vampiros (Barber, 1988, p. 34-35). Mientras estos cuentos tempranos preceden la palabra "vampiro," hay una similitud discernible de la representación de vampiros de la literatura del siglo XIX y subsiguientemente.

Aunque estos relatos tempranos de los muertos resucitándose de la tumba, mayormente europeos, han llegado a muchas narraciones escritas sobre observaciones de vampiros, no todos los investigadores de vampiros creen que el folclore temprano vampírico sea cuentos de vampiros "verdaderos." En su libro El vampiro: una nueva historia, Nick Groom afirma:

Los vampiros no son demonios, fantasmas, espectros, apariciones o brujas-aunque sus historias son entrelazadas a veces. Los vampiros ocupan su propia categoría distinta entre los chupadores de sangre, y asimismo no deben ser demasiado ligados a una bola de miedos generalizados sobre los muertos, los muertos vivientes, el contagio o la muerte. (Groom, 2018, p. 12)

Mientras los relatos de vampiros que preceden el ingreso del vampiro en la literatura abarcan características expansivas, las sugerencias de Groom afirman que los rasgos de personalidad que uno podría asignar a un vampiro "verdadero" podrían ser más estrechos de lo que sugiere el folclore temprano. No está solo en esta creencia.

Montague Summers, en su libro El vampiro en Europa, compara lo que él considera el vampiro "verdadero" con el folclore temprano:

Yo haría hincapié en que la idea vampírica estaba presente entre casi todos los pueblos antiguos, la única gran diferencia, bastante importante pero no cabalmente esencial, siendo que mientras que el vampiro verdadero es un cadáver muerto, los vampiros de supersticiones más antiguas generalmente eran fantasmas o espectros, pero los fantasmas a veces eran tangibles y los espectros podían hacer daño material a los seres vivientes al agotar su vitalidad y vaciar su sangre. (Summers, 1996, p. 64)

Aunque tanto Groom como Summers critican el folclore vampírico como historias de vampiros verdaderas, los dos hombres incluyen muchas historias así en sus obras escritas sobre los vampiros. Por lo tanto, parece que comprenden instintivamente que al tomar el miedo irracional de los humanos primitivos, nacido de la ignorancia de tomar en cuenta los efectos que enfermedades tienen sobre el cuerpo humano, uno podría considerar al vampiro ser cualquier persona o criatura-la mayoría de las veces muerto viviente-que roba la fuerza vital, en la forma de energía, sangre o esencia espiritual de un ser humano. Como mínimo, ambos hombres reconocen que muchos rasgos modernos de vampiros tienen sus raíces en estas representaciones arcaicas de vampiros. Por ende, descartan la idea que estas supersticiones más antiguas también sean vampiros, tal como Summers y Groom nos harían pensar, lo cual sería un error. 
Un ejemplo de un relato arcaico que se aproxima al vampiro ilustra la personificación de lo que muchos considerarían rasgos vampíricos. Un demonio antiguo en un conjuro asirio en escritura cuneiforme sobre siete espíritus, traducido por R. Campbell Thompson en su libro La magia semitica: sus origenes y desarrollo, dice:

Sin saber la piedad, ellos se enfurecen con la humanidad,

Ellos vierten su sangre como la lluvia,

Devorando su carne... chupando sus venas. (Thompson, 1908, p. 48-49)

El libro de Thompson incluye traducciones de otros textos que también describen demonios con características similares a las de los vampiros. Un verso así dice, "Seas un espíritu maligno o demonio malvado... o fantasma de la noche, o espectro de la noche...” (Thompson, 1908, p. 98). Aunque estos espíritus no encajen dentro de la definición de un verdadero vampiro según Groom o Summers, su influencia en la construcción del vampiro moderno es evidente. Por lo tanto, estos relatos tempranos de criaturas similares a los vampiros no se deben descartar como vampiros al intentar comprender la naturaleza de los vampiros.

\section{El nacimiento de la ficción literaria y cine vampíricos}

Cuando relatos de vampiros empezaron a aparecer en la ficción literaria, siguieron el mismo patrón que los vampiros del folclore temprano, en que eran criaturas monstruosas, a las que les faltaba moral rectora. Sin embargo, a menudo estos vampiros tenían la habilidad de imitar la humanidad; pudiendo esconder su lado monstruoso. Este vampiro semejante al ser humano es el comienzo de la evolución de vampiros que al final termina con ellos alcanzando un estado romántico o heroico. Esto es donde empiezan a alejarse del arquetipo de la Sombra y la representación mítica de vampiros de la que hablan Jung y Campbell. Ellos cambian de la subconsciencia a la mente consciente, llegando a ser su propio arquetipo.

La literatura vampírica estuvo de moda en Europa durante el siglo XIX. Desde el folclore y los cuentos de hadas hasta la literatura gótica, los cuentos de vampiros eran muy populares. En Cuentos de hadas de los rusos y otros eslavos, Ace y Olga Pilkington dedican una sección entera a los cuentos de los muertos vivientes a principios del siglo XIX, traducidos de sus idiomas eslavos originales. Estos cuentos en su mayoría prestan autoridad a la idea de que los vampiros son criaturas malvadas-algunas teniendo una notable semejanza con el Drácula de Bram Stoker. Algunos de estos cuentos de hadas bien podrían haber sentado los cimientos de los cuentos de vampiros populares de mediados hasta finales del siglo XIX tales como "El Giaour," El vampiro, Varney el vampiro y Drácula. Estas historias fueron el comienzo de un nuevo paradigma 
de la representación de vampiros, donde estas criaturas malvadas ya no eran relatos históricos de criaturas supuestamente reales que uno debe temer, sino cuentos ficcionales con el propósito de entretener, animar y asustar al lector.

\section{Drácula}

A finales del siglo XIX, el vampiro literario prototípico se solidificó en la forma del conde Drácula, la progenie de El Giaour, Lord Ruthven, Varney, entre otros. Mientras algunas versiones cinemáticas, hasta cierto punto, lo representan como un seductor romántico, su maldad es innegable. No obstante, su historia trágica ha hechizado a sus lectores por siglos.

Vlad el Empalador, ofrecido como la inspiración de Stoker para Drácula, no se parece en nada a él, además que compartir un nombre. En los apuntes personales de Stoker sobre Drácula, solo hay una mención breve del nombre Drácula como referencia a Vlad el Empalador. Sin embargo, en la novela en sí, Van Helsing menciona que un amigo erudito suyo cree, "Él debe haber sido, de verdad, ese Voivode Drácula que ganó su nombre contra el turco, sobre el gran río en la misma frontera de Turquía” (Stoker, 2003, p. 285). Sin embargo, aparte de la sed de la sangre-el caso de Drácula siendo literal y el de Vlad siendo figurativo-Drácula no comparte otras características con Vlad el Empalador. De hecho, Stoker inicialmente consideraba el nombre "el conde Wampyr." Stoker nota que el nombre Drácula significa "diablo" en el idioma wallachian, lo cual probablemente es la razón por el cambio de nombre (Eighteen-Bisang, 2008, p. 244-245). Su nombre aporta credibilidad a la idea que la lucha contra los vampiros es la lucha contra el mal en su forma más pura. ¿Qué nombre mejor para representar la maldad del conde Drácula que un nombre que afirma ser el diablo mismo?

La profesora auxiliar Ani Kokobobo, de la Universidad de Kansas, cree que en vez de la inspiración de Drácula siendo Vlad el Empalador, es más probable que Elizabeth Bathory, conocida como la Condesa Sangrienta, fuera la verdadera inspiración ("La verdad sangrante de los vampiros," 2020). Mientras Drácula sí tiene más en común con la condesa que vacía sangre que con Vlad el Empalador, él se parece más a los vampiros del folclore literario y la ficción.

Drácula fue el fulcro para generaciones de vampiros venideras. El genio de Stoker fue su habilidad de combinar los rasgos vampíricos más interesantes derivados de sus contemporáneos del siglo XIX, además del folclore anterior, para crear una criatura miedosa pero fantástica cuya oscuridad atrae la naturaleza oscura inculcada de la humanidad. Desde su nombre hasta su aspecto físico y supernatural, Stoker pretendía afectar la imagen misma de un monstruo cuando uno escuchó o leyó el nombre Drácula. Van Helsing habla de la astucia de Drácula, tal como la Santa Biblia habla de la serpiente en el Jardín del Edén que "era el más astuto de todos los animales del campo..." (English Standard Version Bible, 2001, Genesis 3:1).

Otras características de Drácula con el propósito de infundir miedo en los corazones de los mortales es tener el control sobre las tormentas y los muertos. Él puede desaparecer de una localidad y reaparecer en otra, convertirse en vapor o polvo, viajar en los rayos de la luz de la luna y entrar en un cuarto por 
medio de la grieta más minúscula-lo cual hace que escapar de él sea casi imposible. Él puede hipnotizar a los seres humanos para que sigan sus órdenes, además que mandar a ratas, búhos, murciélagos, polillas, zorros y lobos, y aun transformarse a sí mismo en lobo o murciélago. Tal vez, aún más espantoso por sus implicaciones hacia los seres humanos es su habilidad de rejuvenecerse cuando se alimenta bien-con la sangre que es la única alimentación que necesita (Stoker, 2003, p. 281-284).

Aun con todos sus poderes, a Drácula no le faltan limitaciones. Aunque tiene la habilidad de entrar en un cuarto por grietas minúsculas, no puede entrar en un lugar al que no le han invitado, pero solo necesita la invitación una vez. Entonces puede continuar a entrar en cualquier momento que desea. Otra limitación suya es la habilidad de cambiar su forma solo al mediodía, al ponerse el sol o al amanecer. Esto le deja más vulnerable si se encuentra en un estado animal. También necesita estar cerca de su tierra casera, la cual mantiene en ataúdes en varios lugares, para poder permanecer con su potencia máxima. Van Helsing informa a sus cazadores acompañantes de otras debilidades de Drácula. Él declara:

Además, hay cosas que lo afectan de tal forma que pierde su poder, como los ajos, que ya conocemos; y en cuanto a las cosas sagradas, como este símbolo, mi crucifijo... La rama de rosal silvestre que se coloca sobre su ataúd le impide salir de él; una bala consagrada disparada al interior de su ataúd lo mata, de tal forma que queda verdaderamente muerto; en cuanto a clavarlo con una estaca de madera, ya conocemos su paz; o a cortarle la cabeza, eso lo hace reposar para siempre. Lo hemos visto con nuestros propios ojos. (Stoker, 2003, p. 284)

De los relatos de vampiros más tempranos hasta los de hoy en día, estos monstruos nunca son completamente invencibles. Si lo fueran, no habría esperanza para la raza humana. Si los vampiros empezaron como un mito que nuestra subconsciencia creó como la personificación de nuestra naturaleza oscura, entonces tener la habilidad de superar el vampiro quiere decir que también poseemos la manera de superar nuestra naturaleza oscura.

Cuando los vampiros llegaron al cine, tal como los relatos de vampiros literarios tempranos, el cine temprano empieza con los vampiros cabalmente monstruosos, y lentamente, se introducen cualidades simpáticas; mostrar la evolución de vampiros de monstruosos a románticos continúa en el cine. La película muda Nosferatu: una sinfonia del horror, producida por Prana Films, y dirigida por F.W. Murnau, era la primera representación cinemática de Drácula. Aunque el personaje vampírico, interpretado por Max Schreck, se llamaba el conde Orlok, las similitudes entre la película y el libro eran lo bastante estrechas para que la viuda de Stoker, Florence Stoker, tuviera éxito al demandar legalmente a Prana Films por violación de los derechos de autor. Tal como el conde Drácula, el conde Orlok no poseía cualidades compensadoras. 
Una de las versiones cinemáticas de Drácula más famosas del siglo XX y la primera para incluir audio, fue la versión de 1931 protagonizada por el actor húngaro Bela Lugosi. No queriendo repetir el error de Prana Films, Universal Pictures obtuvo los derechos para producir su adaptación de la historia de Stoker. Puede que Drácula sea un monstruo por sus hechos en esta adaptación, pero a diferencia del conde Orlok, el personaje de Lugosi no es monstruo de apariencia. Esta versión cinemática es una de las primeras para incorporar un elemento sexual al semblante de Drácula. Su postura se mantuvo recta y su habla clara y concisa. Su ropa nunca estuvo arrugada, y él movía con elegancia y dignidad. Su mirada fija y movimientos lentos hacia el cuello de Mina daban la apariencia de un pretendiente acercándose por un beso, así cultivando la idea de que la naturaleza de un vampiro podría ser multifacética. Esta perversión de la historia original de Drácula-que quita algunos de los rasgos siniestros de Drácula y los reemplaza con características con las que los veedores pueden relacionarse-abre el camino para el vampiro trágico, el antihéroe torturado.

\section{La tragedia de los vampiros de mediados hasta finales del siglo $\mathrm{XX}$}

El folclore temprano, los relatos y el cine del siglo XIX y el siglo XX temprano introdujeron al mundo al vampiro monstruoso. Sin embargo, a mediados del siglo XX, una nueva clase de vampiro empezó a surgir, el vampiro trágico. Aunque estaban en el precipicio entre el bien y el mal, eran dignos de nuestra pena. Estas criaturas solo hacían lo que era su naturaleza hacer. La mayoría de ellos nunca pidieron tener este destino monstruoso. No pueden evitar lo que son, y como el héroe byroniano, ellos desprecian su misma naturaleza y lamentan su destino. En su artículo "Rehabilitando apariciones, o vampiros compasivos en la ficción reciente," Joan Gordon refiere a estos vampiros como los vampiros compasivos (Gordon, 2011, p. 227-233). Sin embargo, referirse a estas criaturas como compasivas es un nombre no apropiado. Insinúa que ellos sienten compasión por otros; no obstante, por lo general son criaturas egoístas. Se quejan por el hecho de que sean "monstruos," que les falte el amor, que hayan matado para sobrevivir. La melancolía sería mejor palabra para describir estas criaturas trágicas que no pueden ver más allá de su propio dolor. Relatos literarios y cinemáticos tales como Sombras tenebrosas, Entrevista con el vampiro y Drácula, la historia jamás contada son el puente entre el vampiro monstruoso y el romántico. Para que ocurra un cambio de monstruoso a romántico, el vampiro primero debe aprender a odiar su misma naturaleza, tal como en la Santa Biblia se dice a la humanidad que "Aborrezcan el mal; aférrense al bien" (English Standard Version Bible, 2001, Romans 12:9b). Un programa de televisión, en particular, ilustra el auto odio del vampiro-Forever Knight.

\section{Forever Knight}

El programa de televisión de 1992-1996 Forever Knight sigue la historia de Nick Knight, un vampiro policía que vive y trabaja en Toronto, Canadá. Knight, de ochocientos años de edad, era la personificación del vampiro trágico. Su desdén por su estado y las atrocidades que cometió sobre los seres 
humanos a lo largo de cientos de años fue tan arrollador que estaba en lucha constante para combatir su naturaleza. Knight hizo lo mejor que pudo para evitar beber la sangre humana por medio de consumir la sangre de animales. Ya no mataba indiscriminadamente, sino que escogió usar sus poderes vampíricos solo cuando fuera necesario-por lo general en acto de servicio. Natalie Lambert, la amiga de Knight, quien está enamorada de él secretamente, es el único ser humano que sabe que Knight es un vampiro. Al final de la última temporada, ella ruega a Knight que la convierta en vampiresa. Él se da por vencido y comienza la transformación, pero antes que pueda completarlo, se da cuenta que no puede dejar que Lambert sufra el mismo destino que él ha estado luchando por tanto tiempo y la deja morir en vez de convertirla en lo que él percibe ser un estado monstruoso. Entonces en un ataque de arrepentimiento, él ruega a otro vampiro que le ayude poner fin a su vida. Este fin aproximando el de Romeo y Julieta solidifica la historia entre las tragedias cinemáticas.

Lo que hace que los vampiros como Nick Knight sean tan trágicos es que, aunque desprecian su propia naturaleza, no pueden superarlo sin importar lo arduamente que intentan hacerlo, tal como dice el apóstol Pablo en Romanos 7:15, "No entiendo lo que me pasa, pues no hago lo que quiero, sino lo que aborrezco" (English Standard Version Bible, 2001, Romans 7:15). Tal como esta escritura ilustra, los seres humanos no desconocen la lucha contra su propia naturaleza.

Campbell dice, "Los mitos inspiran la comprensión de la posibilidad de su perfección, la plenitud de su fuerza y la llegada de la luz solar al mundo. Matar monstruos es matar las cosas oscuras" (148). A lo cual Moyers pregunta a Campbell, “¿Cómo mato al dragón dentro de mí?” (148). Como respuesta Campbell dice, "Por lo general mi fórmula... es 'Siga su felicidad. Encuentre dónde está, y no tenga miedo de seguirla” (p. 148). La inhabilidad de Nick de lograr la felicidad se enraizó en su inhabilidad de darse cuenta de la posibilidad de su perfección.

\section{De la tragedia surge el romanticismo}

Mientras el arquetipo de vampiro monstruoso domina la literatura folclórica temprana y la literatura del siglo XIX, y el arquetipo del vampiro trágico perdido y solo surge en la literatura del siglo XX, la literatura y el cine del silgo XXI dan al público lo que quiere, el vampiro maligno convertido en trágico, la redención en la forma del arquetipo del vampiro romántico. Estos vampiros eran los héroes que superaron su pasado dañado, lo cual hace que esta nueva era de vampiros sea tan seductiva. Similarmente a los hombres, el vampiro moderno busca salvación. En el libro El poder del mito, Bill Moyers llama al cielo "[E]sa meta deseada de la mayoría de la gente" (Campbell \& Moyers, 1998, p. 39). Para que el vampiro obtenga esa meta, tiene que llegar a ser más que una criatura mala o trágica. Debe llegar a ser el héroe.

Cuando el vampiro casi héroe romántico llegó a su auge en el mundo literario durante el siglo XXI, los escritores sacaron el máximo rendimiento de esta nueva moda en las historias vampíricas. Este nuevo modelo de vampiros a veces se dedicaba a la destrucción de vampiros malignos. Campbell declara, 
"Tanto si uno llama a alguien un héroe o un monstruo es totalmente en relación con dónde puede estar el enfoque de su consciencia” (Campbell \& Moyers, 1998, p. 127). El enfoque de la consciencia del siglo XXI estaba en la necesidad de un héroe. Los escritores explotaron esta necesidad y sedujeron a los lectores a creer que los vampiros no son malos. Estos autores hipnotizan a los lectores con cuentos del bien contra el mal, donde al fin y al cabo el bien vence al mal.

Los autores modernos no solo están creando vampiros que ya no son tan espantosos como sus predecesores del silgo XIX, sino también están inventando reglas completamente nuevas para lo que se define como un vampiro y a veces de cómo llegaron a serlo. Que los vampiros tengan una aversión al ajo no es una garantía. A muchos no les falta el alma. Solo para nombrar unas cuantas series de vampiros románticos modernos, hay la serie Cazadores oscuros de Sherrilyn Kenyon, la saga Crepúsculo de Stephanie Meyer y la serie Argeneau de Lynsay Sands-una historia de vampiros con orígenes inusuales que caben perfectamente en la representación romántica posdemónica del vampiro heroico.

\section{La serie Argeneau}

Lynsay Sands tiene una interpretación única en cuanto a sus vampiros. Los primeros vampiros eran de Atlántida, una raza de seres humanos avanzados cuyos doctores crearon nanobots diminutos para entrar en el torrente sanguíneo de los que tenían enfermedades graves para atacar y destruir esas enfermedades. La intención era que estos nanobots murieran al terminar de curar al paciente. A pesar de su inteligencia avanzada, los doctores atlantes fallaron en predecir que a causa de que el cuerpo humano siempre estaba siendo atacado por padecimientos y enfermedades, los nanobots nunca morirían. Estos nanobots hasta consideraban el envejecer una enfermedad que necesitaba curarse. Cualquier ser humano podría llegar a ser un vampiro con la introducción de nanobots en su flujo sanguíneo. Una vez que llegaron a ser vampiros, los nanobots cambiaban la composición de sus genes hasta llegar a su edad perfecta, y su cuerpo llegara a su condición perfecta. Si una persona de tercera edad con sobrepeso llegó a ser vampiro, de repente se encontrarían con la apariencia y sentimiento de alguien de 25 años de buena salud. Llegaron a ser la versión perfecta de sí mismos. Estos rasgos de vampiros atraen a los ideales humanos de la perfección física.

Cuando Atlántida cayó, solo los atlantes con los nanobots adentro de ellos sobrevivieron. Sin embargo, ya que el resto del mundo estaba lejos de lo avanzado que eran los atlantes y no tenían bancos de sangre, los nanobots evolucionaron a sus huéspedes para poder extraer la sangre por medio de sus dientes tipo pajita para conseguir lo que necesitaban de otros humanos. También evolucionaron a sus huéspedes para poder leer los pensamientos de los humanos, y hasta otros atlantes, con el propósito de calmar y controlar a aquellos de los de que se alimentaban. 
Tal como los seres humanos, entre sus cuentos, hay vampiros virtuosos y vampiros inescrupulosos. Algunos de estos vampiros nobles y morales se encargan de proteger la humanidad del intento de los malignos de cometer hechos malvados, estableciendo a los vampiros buenos como figuras heroicas o románticas. Aunque estos vampiros tienen fuerza superior, el oído excepcional, la visión aumentada y tienen que beber sangre para sobrevivir, de ninguna forma se parecen a los monstruos de relatos anteriores. No son más malos que cualquier otro ser humano. Una vez que la civilización avanzó hasta el punto de tener bancos de sangre, los inmortales hasta crearon leyes en contra de beber sangre directamente de los humanos, en vez de sangre en bolsa, salvo en una emergencia, además de otras leyes con el fin de mantenerlos bajo control y proteger a los humanos.

Para aumentar el impacto romántico de sus vampiros, Sands le da a cada uno un amor verdadero, llamado lifemate (pareja de por vida), a quien siempre buscan. Cuando un vampiro conoce a su posible lifemate, tiene ciertos rasgos que reconoce. No puede leer la mente de su lifemate ni controlarlo. En el libro de Sands Vampiro interrumpido, el vampiro Julius dice a su lifemate, "Marguerite, somos lifemates. No puedo leerte ni controlarte" (Sands, 2009, p. 230). Este no fue el único rasgo que compartieron Marguerite y Julius que les etiquetó como lifemates. Los lifemates comparten sueños si están en proximidad cercana y durmiendo a la misma vez. Vampiros sin pareja, después de unos cien o doscientos años de existencia, pierden el interés con cosas como la comida y el sexo. Sin embargo, si ambos, o solo uno de una pareja de lifemates eran vampiros al conocerse, de repente se encontrarían con un interés renovado en la comida y la cópula. Los lifemates eran almas gemelas, y este amor perfecto se buscaba entre la mayoría de los vampiros.

Estos vampiros románticos han llegado a un estado que el vampiro trágico codicia - un estado en que son más que solo monstruos. Al volverse dignos del amor, el vampiro transciende del vampiro monstruoso al vampiro trágico al vampiro romántico. Aunque la jornada del vampiro del mito del monstruo al arquetipo romántico corre en paralelo a la jornada de la humanidad de pecador a redimido, ni los vampiros ni los humanos se han deshecho completamente de su naturaleza oscura. La han reprimido y han dejado que el bien dentro de ellos mismos brille más que el mal. El Nuevo Testamento, 1 Juan 1:8 describe cómo todas las personas tienen este lado más oscuro, o pecado, y dice, " $\mathrm{Si}$ afirmamos que no tenemos pecado, lo único que hacemos es engañarnos a nosotros mismos, y no vivimos en la verdad" (English Standard Version Bible, 2001, 1 John 1:8). Aunque tiene un lado oscuro reprimido, el vampiro romántico moderno ha superado el estigma del vampiro monstruoso y la desesperación del vampiro trágico y ha metamorfoseado de villano a héroe. Cuando Moyers pregunta a Campbell, "¿Así que el héroe evoluciona con el tiempo tal como la mayor parte de otros conceptos?” 
Campbell responde, "Evoluciona mientras evoluciona la cultura" (Campbell \& Moyers, 1998, p. 135). Tal como el arquetipo antiguo del héroe, el vampiro ha evolucionado para cumplir las necesidades de la sociedad hoy en día. Ha evolucionado en héroe.

\section{La conclusión: fuera de la Sombra}

El arquetipo de la Sombra de Jung es el lado oscuro de la psique humana. Este lado oscuro da a luz al mito del monstruo subconsciente, con el mito del vampiro siendo una manifestación del mito del monstruo. Al cambiar de la subconsciencia a la mente consciente de la humanidad-ir de relatos surgidos del miedo generalizado a la literatura ficcional con el propósito de entretener-los vampiros cambian de mito a arquetipo. De la misma manera, la naturaleza oscura humana cambia de desconocida a conocida, o de la subconsciencia a la consciencia, o como dice Jung, de la inconsciencia a la consciencia.

El arquetipo del vampiro más temprano es innegablemente un monstruo. Vacía la fuerza vital de sus víctimas, chupando su sangre y devorando su carne. No conoce otra senda que el camino a la perdición. Este monstruo representa la naturaleza oscura de la humanidad, pero a diferencia que el mito vampírico, este vampiro, tal como algunos de sus contemporáneos humanos, conoce su naturaleza y no tiene el deseo de ser otra cosa que lo que es, un monstruo.

Como los humanos, algunos vampiros, al ser conscientes de sí mismos, se repugnaba por quiénes eran y añoraban ser más, purificarse. Estos vampiros son el arquetipo del vampiro trágico, el vampiro que aborrece su propia existencia. Vive una vida de autosacrificio por la culpa y una necesidad de redención. Su arrepentimiento sale del miedo a la condenación y al temor del monstruo dentro de sí.

El tercer arquetipo vampírico para separarse del mito vampírico y evolucionar del vampiro monstruoso y trágico es el vampiro romántico. El vampiro romántico es protector, amante, ejemplo, y ha encontrado su salvación en esta existencia. Y aunque todavía lleva dentro una naturaleza oscura reprimida, lo que hace que el vampiro romántico sea un héroe es su habilidad de resistir la tentación de rendirse a su naturaleza oscura, aunque como los humanos, a veces siente que la tentación es casi aplastante. Cuando el vampiro evoluciona del vampiro trágico al vampiro romántico, ha llegado a su estado deseado. Para los judeocristianos y muchas otras religiones, esto sería cuando encuentran su salvación. Para los de otras ciertas religiones, además de aquellos sin creencias religiosas, esto podría ser cuando han llegado al auge de lo que desean ser.

De la misma manera en que los humanos siempre tendrán su naturaleza pecaminosa o el yo de la Sombra, siempre existirá dentro de los tres arquetipos de vampiros un grano del mito de la Sombra, una semilla de esa naturaleza pecaminosa. El vampiro evoluciona mientras nosotros evolucionamos. Y tal como los humanos, no todos los vampiros evolucionan hasta un estado exaltado. Algunos nunca dejan atrás el arquetipo monstruoso o el arquetipo trágico, tal como la literatura y el cine no los ha dejado atrás. 
Campbell declara, "Lo que llamamos monstruos pueden ser percibidos como sublimes... está subiendo, hasta de repente rompe más allá de una nubosidad y una expansión del horizonte se abre, y de alguna manera, con esta disminución de su propio ego, su consciencia se expande hasta una experiencia de lo sublime" (Campbell \& Moyers, 1998, p. 222). Tanto si hablamos sobre vampiros o humanos, aquellos con la meta de la salvación de su ego monstruoso y los que trabajan para esa meta encontrarán de repente que han llegado a su destinación, y entonces de verdad pueden experimentar la felicidad.

\section{Nota del traductor}

Todas las traducciones de citas y nombres de obras en el texto fueron realizadas por el traductor, pero se dejan como originales en las referencias. 


\section{REFERENCES}

archetype, n. (2020). In Oxford English Dictionary. https://www-oed-com.libproxy.dixie.edu/view/ Entry/10344? redirectedFrom=archetype\#eid

Bane, T. (2020). Encyclopedia of Vampire Mythology. McFarland \& Company, Inc.

Barber, P. (1988). Vampires, Burial Eं Death. Yale University.

Bleeding Truth about Vampires, The. (2020). KU College Stories. http://blog.college.ku.edu/thebleeding-truth-about-vampires-soucouyants-and-the-undead/

Borchiver, R. P. (Producer). (1996). Forever Night [Television Series].

Browning, T. (Director). (1931). Dracula [Motion Picture].

Campbell, J., \& Moyers, B. (1998). The Power of Myth (B. S. Flowers, Ed.). Double Day.

Cooper, B. (2005). The Word "Vampire": Its Slavonic Form and Origin. Journal of Slavic Linguistics, 262.

Eighteen-Bisang, M. E. (2008). Bram Stoker's Notes for Dracula: A Facsimile Edition. McFarland \& Company, Inc.

English Standard Version Bible. (2001). Crossway. https://www.esv.org/

Gallagher, S. M. (2017). The Irish Vampire From Folklore to the Imaginations of Charles Robert Maturin, Joseph Sheridan Le Fanu and Bram Stoker. McFarland \& Company, Inc.

Gordon, J. (2011). Rehabilitating Revenants, or Sympathetic Vampires in Recent Fiction. 29(3), 227-233. https://search.proquest.com/scholarly-journals/rehabilitating-revenants-sympatheticvampires/docview/1304234370/se-2? accountid $=147094$

Groom, N. (2018). The Vampire A New History. Gomer Press Ltd. https://doi.org/10.2307/ j.ctv6gqxp2

Johnson, S., \& Oldys, W. (Eds.). (1745). The Travels fo Three English Gentlemen: Vol. IV. T. Osborne, in Gray's-Inn.

Jung, C. G. (1968). Collected Works of C.G.Jung (R. Hull, Trans.; 2nd ed., Vol. 9). Princeton University Press.

Jung, C. G. (2006). The Undiscovered Self(R. Hull, Trans.). SIGNET.

Melton, J. G. (1994). The Vampire Book: The Encyclopedia of the Undead. Visible Ink Press.

Murnau, F. W. (Director). (1922). Nosferatu: A Symphony of Horror [Motion Picture].

Pilkington, A., \& Pilkington, O. (2009). Fairy Tales of the Russians and Other Slavs. Forest Tsar Press.

Sands, L. (2009). Vampire Interrupted. Harper Collins.

Stoker, B. (2003). Dracula. Barnes \& Noble Books.

Summers, M. (1929). The Vampire - His Kith and Kin (T. E. K. Paul Trench, Ed.).

Summers, M. (1996). The Vampire in Europe. Random House Value Publishing, Inc.

Thompson, R. C. (1908). Semitic Magic: Its Origins and Development. Luzac \& Co.

vampire, n. (2020). In Oxford English Dictionary: The Definitive Record of the English Language. https://www-oed-com.libproxy.dixie.edu/view/Entry/221303? rskey=Rw0C06\&result=1\#eid

Wilson, K. M. (1985). The History of the Word "Vampire." Journal of the History of Ideas, 46(4), 577. https://doi.org/10.2307/2709546 